\title{
PENGOLAHAN LANJUT LIMBAH CAIR KELAPA SAWIT SECARA AEROBIK MENGGUNAKAN EFFECTIVE MICROORGANISM GUNA MENGURANGI NILAI TSS
}

\author{
Irvan, Bambang Trisakti, Michael Vincent, Yohannes Tandean \\ Departemen Teknik Kimia, Fakultas Teknik, Universitas Sumatera Utara \\ Jl. Almamater Kampus USU Medan 20155, Indonesia \\ email : i_v_a_n_mz@yahoo.com
}

\begin{abstract}
Abstrak
Produksi limbah cair pabrik kelapa sawit (palm oil mill effluent, POME) di Indonesia diperkirakan sebesar 28,7 juta ton/tahun. Umumnya pengolahan POME dilaksanakan secara konvensional yaitu dengan menggunakan sistem kolam (pond). Selain memerlukan biaya operasional dan memerlukan lahan yang luas, sistem ini juga menghasilkan emisi gas rumah kaca. Padahal POME merupakan bahan baku potensial untuk menghasilkan biogas. Penelitian terdahulu telah dilaksanakan dengan proses anaerob untuk mendapatkan biogas, akan tetapi limbah yang dihasilkan masih tidak memenuhi standar mutu. Nilai TSS yang dihasilkan dari pengolahan anaerob masih berkisar $400 \mathrm{mg} / \mathrm{l}$. Oleh karena itu diperlukan proses aerob untuk menurunkan nilai TSS dengan bantuan effective microorganism. Dari hasil penelitian proses aerob HRT 10 hari didapat penurunan nilai TSS sampai sekitar $200 \mathrm{mg} /$.
\end{abstract}

Kata kunci: Biogas, TSS, Effective Microorganism, POME

\begin{abstract}
Palm oil mill effluent (POME) production in Indonesia is estimated around 28.7 million ton/year. Generally, POME treatment is done conventionally by using facultative ponds. Aside from the vast usage of land and operational cost, this system also emits greenhouse gases. Eventhough, POME is a potential raw resource in producing biogas. Previous researches were done with anaerobic process to produce biogas, but the waste produced still haven't met the standard quality control requirements. The total suspended solid (TSS) contained in the waste produced from the anaerobic process is still around 400 $\mathrm{mg} / \mathrm{L}$, which is the reason why aerobic process is still necessary to drop the number of TSS contained by using effective microorganism. From the result, a 10 day HRT aerobic process can reduce the number of TSS to around $200 \mathrm{mg} / \mathrm{L}$.
\end{abstract}

Keywords : Biogas, TSS, Effective Microorganism, POME

\section{Pendahuluan}

Minyak sawit merupakan produk perkebunan yang memiliki prospek cerah di masa mendatang. Potensi tersebut terletak pada keragaman kegunaan dari minyak sawit. Minyak sawit disamping digunakan sebagai bahan mentah industri pangan, dapat pula digunakan sebagan bahan mentah industri non pangan. [1]

Dalam perekonomian Indonesia komoditas kelapa sawit memegang peranan yang cukup strategis karena komoditas ini mempunyai prospek yang cerah sebagai sumber devisa. Disamping itu minyak sawit merupakan bahan baku utama minyak goreng yang banyak dipakai di seluruh dunia, sehingga terus menerus mampu menjaga stabilitas harga minyak sawit. Komoditas ini pun mampu pula menciptakan kesempatan kerja yang luas dan meningkatkan kesejahteraan masyarakat. [1]

Saat ini Indonesia adalah penghasil minyak kelapa sawit terbesar di dunia seperti yang terlihat pada Gambar 1.

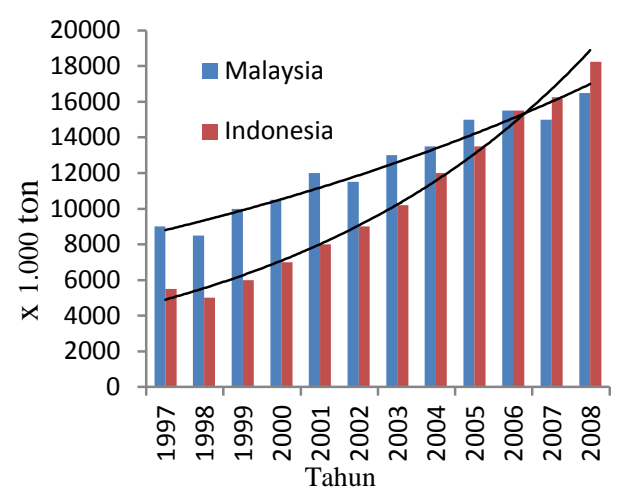

Gambar 1. Perbandingan Produksi Minyak Kelapa Sawit di Indonesia dan Malaysia [2]

Kebun dan pabrik kelapa sawit (PKS) menghasilkan limbah padat dan cair (palm mill oil effluent, POME) dalam jumlah yang sangat besar, sehingga harus diolah. Pengolahan POME secara anaerobik dapat menghasilkan biogas dan dapat menurunkan nilai TSS. Tetapi nilai TSS yang dihasilkan dari pengolahan anaerobik masih terlalu tinggi untuk dapat dibuang ke badan air, yaitu sekitar 400 mg/l. Oleh karena itu masih diperlukan 
pengolahan lanjut dengan bantuan Effective Microorganism (EM).

Teori

POME adalah limbah cair kelapa sawit yang masih mengandung banyak padatan terlarut. Sebagian besar padatan terlarut ini berasal dari material lignoselulosa mengandung minyak yang berasal dari buah sawit. Lignoselulosa dalam POME adalah penyusun terbanyak dari tanaman berkayu. Lignoselulosa terdiri dari lignin, hemiselulosa, dan material berselolosa. Kandungan kimiawi dari lignoselulosa ini membuat mereka bernilai tinggi dari segi bioteknologi [3]

Kebanyakan dari limbah lignoselulosa ini dibuang langsung dengan cara pembakaran, dimana hal ini tidak dilarang di negara berkembang. Namun, akan muncul masalah ketika biomassa ini tidak diperlakukan dengan baik dan dibiarkan membusuk di areal pertanaman, dimana kedepannya akan terjadi penumpukan kandungan organik yang terlalu tinggi. Oleh sebab itu, manajemen lingkungan memberikan tekanan yang besar di pengurangan limbah dari sumbernya ataupun proses daur ulang.[3]

Adapun karakteristik dari limbah cair pabrik kelapa sawit terlihat pada Tabel 1 .

Tabel 1. Karakteristik limbah cair pabrik kelapa sawit [4]

\begin{tabular}{|c|l|c|c|}
\hline No & \multicolumn{1}{|c|}{ Parameter } & Satuan & Kisaran \\
\hline 1 & $\begin{array}{l}\text { Biological } \\
\text { Oxygen Demand } \\
(\text { BOD })\end{array}$ & $\mathrm{mg} / \mathrm{l}$ & $20.000-30.000$ \\
\hline 2 & $\begin{array}{l}\text { Chemical } \\
\text { Oxygen Demand } \\
\text { (COD) }\end{array}$ & $\mathrm{mg} / \mathrm{l}$ & $40.000-60.000$ \\
\hline 3 & $\begin{array}{l}\text { Total Suspended } \\
\text { Solid (TSS) }\end{array}$ & $\mathrm{mg} / \mathrm{l}$ & $15.000-40.000$ \\
\hline 4 & Total Solid (TS) & $\mathrm{mg} / \mathrm{l}$ & $30.000-70.000$ \\
\hline 5 & $\begin{array}{l}\text { Minyak dan } \\
\text { Lemak }\end{array}$ & $\mathrm{mg} / 1$ & $5.000-7.000$ \\
\hline 6 & NH ${ }_{3} \mathrm{~N}$ & $\mathrm{mg} / 1$ & $30-40$ \\
\hline 7 & Total N & $\mathrm{mg} / 1$ & $500-800$ \\
\hline 8 & Suhu & ${ }^{\circ} \mathrm{C}$ & $90-140$ \\
\hline 9 & $\mathrm{pH}$ & - & $4-5$ \\
\hline
\end{tabular}

Sedangkan standar mutu limbah cair kelapa sawit supaya dapat dibuang ke badan perairan Indonesia terlihat pada Tabel 2.
Tabel 2. Standar Mutu Limbah Cair Pabrik Kelapa Sawit [5]

\begin{tabular}{|c|c|c|}
\hline Parameter & Satuan & $\begin{array}{c}\text { Kadar } \\
\text { Maksimum }\end{array}$ \\
\hline $\mathrm{BOD}$ & $\mathrm{mg} / \mathrm{L}$ & 100 \\
\hline $\mathrm{COD}$ & $\mathrm{mg} / \mathrm{L}$ & 350 \\
\hline $\mathrm{TS}$ & $\mathrm{mg} / \mathrm{L}$ & 5.000 \\
\hline $\mathrm{TSS}$ & $\mathrm{mg} / \mathrm{L}$ & 250 \\
\hline Minyak dan Lemak & $\mathrm{mg} / \mathrm{L}$ & 25 \\
\hline $\mathrm{NH}_{3}-\mathrm{N}$ & $\mathrm{mg} / \mathrm{L}$ & 20 \\
\hline $\mathrm{pH}$ & - & $6-9$ \\
\hline $\begin{array}{c}\text { Debit Limbah } \\
\text { Maksimum }\end{array}$ & $\begin{array}{c}\mathrm{m}^{3} / \mathrm{ton} \\
\mathrm{produksi}\end{array}$ & 6 \\
\hline
\end{tabular}

Effective Microorganisms (EM) adalah campuran dari kultur mikroorganisme menguntungkan dan alami (terutama bakteri fotosintesis dan asam laktat, ragi, aktinomycetes dan jamur fermentasi). Mikroorganisme menguntungkan ini meningkatkan pertumbuhan tanaman dan hasil dengan cara meningkatkan fotosintesis, memproduksi substansi bioaktif seperti hormon dan enzim, mengontrol penyakit dari tanah, dan mempercepat proses dekomposisi material lignin dalam tanah. [6]

\section{Metodologi Penelitian}

Penelitian dilaksanakan di Departemen Teknik Kimia Fakultas Teknik USU, dan Pusdiklat LPPM USU dengan bahan berupa limbah hasil pengolahan POME dari Pilot Plant LPPM USU dan Effective Microorganism.

Untuk pengolahan POME secara aerob, maka diperlukan sebuah reaktor dan aerator. Berikut Gambar 2. menunjukkan reaktor dan perangkatnya yang digunakan untuk mengolah POME secara aerob pada penelitian ini.

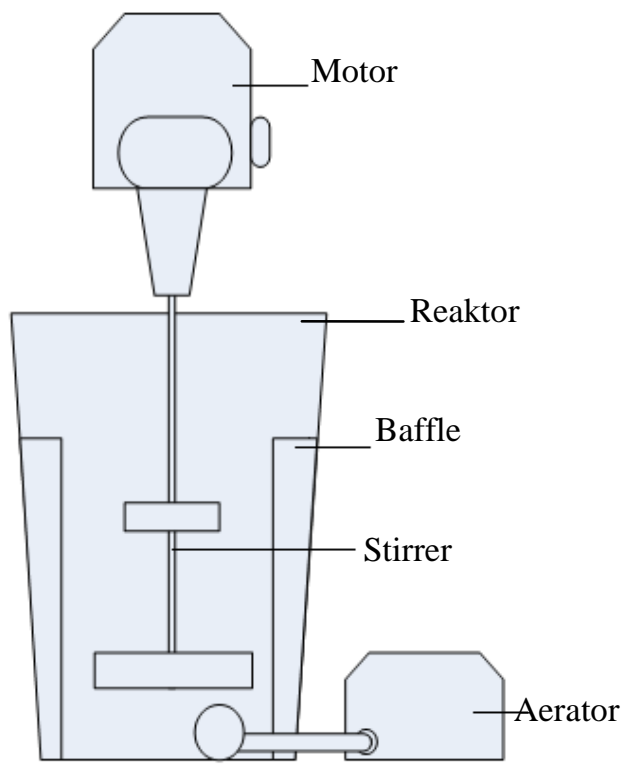

Gambar 2. Rangkaian Peralatan Utama 
Fungsi dari masing-masing alat yg diperlihatkan pada Gambar 2. adalah sebagai berikut :

1. Motor: Penggerak stirrer.

2. Reaktor : Wadah tempat dilakukan penelitian sampel dan EM.

3. Baffle : Untuk mencegah terjadinya pengadukan searah di dalam reaktor.

4. Stirrer : Mengaduk isi reaktor supaya terjadi pencampuran secara merata.

5. Aerator: Menyalurkan udara kedalam reaktor.

Peralatan analisa yang digunakan pada penelitian ini adalah :

1. Oven

2. Desikator

3. Cawan Penguap

4. Timbangan elektrik

5. Furnace

6. Gelas ukur

7. Beaker Glass

8. Corong Gelas

Prosedur pengaktifan Effective

Microorganisms supaya dapat digunakan pada penelitian ini :

1. Dipanaskan air sebanyak 4 liter dan dileburkan gula aren 100 gram dalam air.

2. Campuran air dan gula didiamkan sampai suhu kamar.

3. Ditambahkan sebanyak $40 \mathrm{~mL}$ Effective Microorganisms ke dalam campuran gula aren dan air.

4. Campuran tersebut ditutup rapat dan disimpan dalam ruang sejuk dan gelap selama 72 jam.

Prosedur pelaksanaan penelitian ini adalah sebagai berikut :

1. Campuran bakteri sebanyak 2 liter dimasukkan kedalam tangki.

2. Ditambahkan sebanyak 2 liter campuran limbah dan air dengan perbandingan 1:4 ke dalam tangki.

3. Dihidupkan pengaduk dengan kecepatan putaran sebesar $10 \mathrm{rpm}$ pada tangki pertama dan 20 rpm pada tangki kedua.

4. HRT awal dimulai dengan HRT 40 hari.

5. Demikian seterusnya hingga mencapai target HRT yaitu HRT 10 hari.

\section{Hasil}

1. Penyisihan TSS dengan Hari pada Tangki Pertama dengan Kecepatan Putaran Pengaduk 10 rpm
Hasil penelitian dari penyisihan TSS dengan hari yang diperoleh pada tangki pertama dapat dilihat pada Gambar 3.

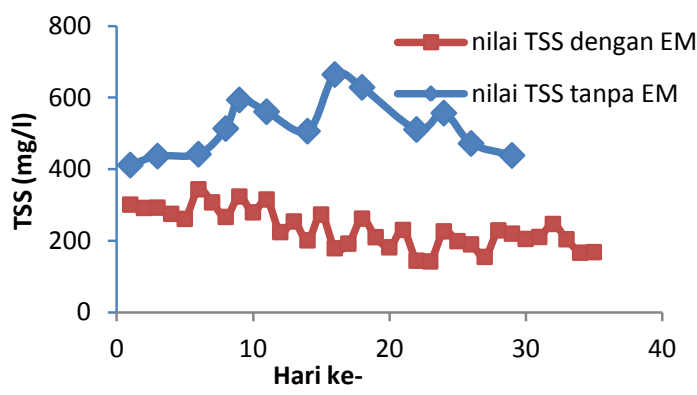

Gambar 3. Grafik Penyisihan TSS dengan Hari pada Tangki Pertama

Nilai TSS dengan penggunaan EM yang diperoleh cenderung menurun seiring dengan bertambahnya hari, sedangkan nilai TSS tanpa penggunaan EM yang diperoleh cenderung naik seiring dengan bertambahnya hari. Nilai TSS dengan penggunaan EM lebih rendah daripada tanpa EM. Nilai TSS dengan penggunaan EM cenderung menjadi lebih stabil pada hari-17 dan mulai naik pada hari ke-29.

Dari teori, diketahui bahwa kadar TSS akan semakin menurun seiring dengan bertambahnya hari, kemudian akan menjadi stabil dan naik dan akhirnya akan turun lagi. Hal ini disebabkan bakteri akan mengurai padatan yang terkandung dalam POME dan mengubahnya menjadi zat makanan, sehingga nilai TSS pada tangki akan semakin menurun seiring dengan bertambahnya hari, dan pada akhirnya akan menjadi stabil dan naik disebabkan kematian bakteri pengurai yang akan meningkatkan nilai TSS. [7,8]

2. Penyisihan TSS dengan Hari pada Tangki Kedua dengan Kecepatan Putaran Pengaduk 20 rpm

Hasil penelitian dari penyisihan TSS dengan hari yang diperoleh pada tangki kedua dapat dilihat pada Gambar 4.

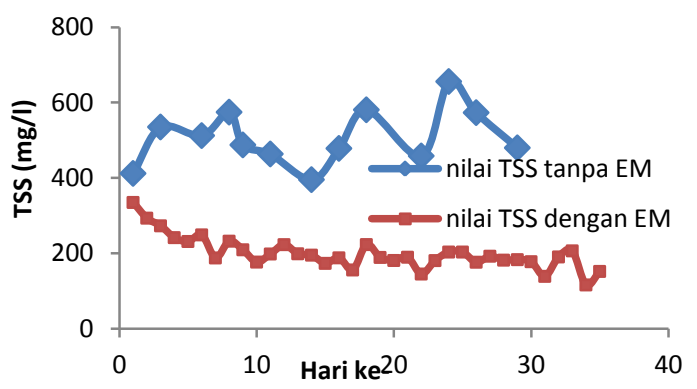

Gambar 4. Grafik Penyisihan TSS dengan Hari pada Tangki Kedua 
Dari Gambar 4. dapat diketahui bahwa nilai TSS dengan penggunaan EM yang diperoleh pada percobaan, cenderung menurun seiring dengan bertambahnya hari. Sedangkan nilai TSS tanpa penggunaan EM yang diperoleh cenderung naik seiring dengan bertambahnya hari. Nilai TSS dengan penggunaan EM cenderung menjadi lebih stabil pada hari-22 dan mulai naik pada hari ke-30.

Seiring dengan bertambahnya hari, maka kadar TSS akan semakin menurun, kemudian akan menjadi stabil, naik lagi, dan akhirnya akan turun. Hal ini sejalan dengan teori, dimana naik turunya nilai TSS disebabkan kinerja bakteri EM. Bakteri akan mengurai padatan yang terkandung dalam POME dan mengubahnya menjadi zat makanan, sehingga nilai TSS pada tangki akan semakin menurun seiring dengan bertambahnya hari, dan pada akhirnya akan menjadi stabil dan naik sedikit, disebabkan kematian bakteri pengurai yang akan meningkatkan nilai TSS. [7,8]

\section{Penyisihan TSS Pada Tangki Pertama (10 rpm)} dengan Tangki Kedua (20 rpm)

Hasil penelitian dari penyisihan TSS dengan hari yang diperoleh pada kedua tangki dapat dilihat pada Gambar 5.

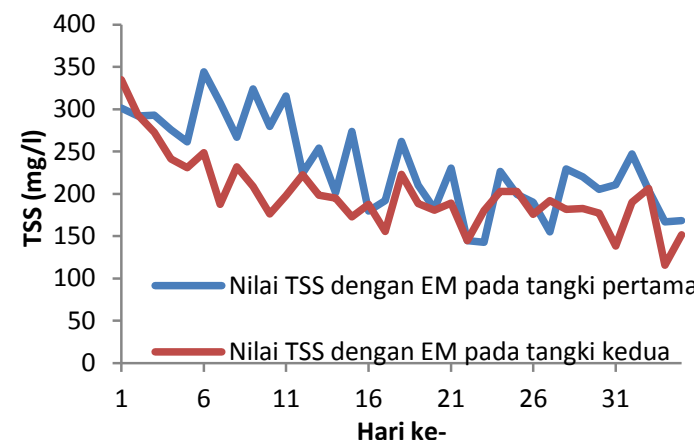

Gambar 5. Grafik Penyisihan TSS Pada Tangki Pertama (10 rpm) dengan Tangki Kedua (20 rpm)

Dari hasil percobaan yang diperoleh, dapat dilihat bahwa pada gambar 5. nilai TSS dengan penggunaan EM pada tangki kedua cenderung lebih rendah daripada nilai TSS dengan penggunaan EM pada tangki kedua.

Dari teori yang didapat, didapati bahwa semakin tinggi kecepatan pengaduk, maka penurunan TSS akan semakin kecil, hal ini disebabkan bakteri tidak bisa bekerja secara optimal pada pengadukan yang terlalu cepat. [9]

\section{Kesimpulan}

Adapun kesimpulan yang didapat dari penelitian ini adalah sebagai berikut:

1. Semakin tinggi kecepatan pengaduk (20 rpm), maka kinerja bakteri dalam mengurai TSS semakin rendah.

2. Nilai TSS baik pada tangki dengan kecepatan putaran $10 \mathrm{rpm}$ dan $20 \mathrm{rpm}$ cenderung menurun seiring dengan waktu.

3. Nilai TSS dengan penggunaan EM jauh lebih rendah daripada tanpa penggunaan EM.

4. Nilai TSS yang berkisar $200 \mathrm{mg} / \mathrm{l}$ sudah dapat langsung dibuang ke badan air.

\section{Daftar Pustaka}

[1] Risza, Suyatno, Upaya Peningkatan Produktivitas Kelapa Sawit. Penerbit Kanisius, Yogyakarta, Indonesia, 1994.

[2] Risza, Suyatno, Masa Depan Perkebunan Kelapa Sawit di Indonesia. Penerbit Kanisius, Yogyakarta, Indonesia, 2010.

[3] Ibrahim, M, 3rd Kuala Lumpur International Conference Engineering. Bio-Composting Process Development by SFF for Utilization Agro-Industrial Waste. Springer Berlin Heidelberg, New York, 2006

[4] Singh, Vijay, Wastewater Treatment and Waste Management. Allied Publishers Pvt Ltd, 2003.

[5] Keputusan Menteri Negara Lingkungan Hidup Nomor 51 Tahun 1995

[6] Javaid, Arshad, Genetic Engineering, Biofertilisation, Soil Quality and Organic Farming. Springer Link Sustainable Agriculture Reviews, Volume 4, pp. 347-369, 2010.

[7] Lumbangaol, Pendi. Pedoman Pembuatan Dosis Pupuk Kelapa Sawit. Penerbit Penebar Swadaya, Bogor, 2006.

[8] Szymanski, Nathan, et al. Effective Microorganism (EM) and Wastewater Systems. Published by Lanfax Laboratories Armidale. ISBN 0-9579438-1- 4 pp. 347-354, 2003.

[9] Jeantet, Romain, et al, The influence of stirring speed, temperature and solid concentration on the rehydration time of micellar casein powder. Springer Link Volume 90, Numbers 2-3, pp. 225-236, 2010. 